\title{
Purification of Immunoglobulins and their Binding to a Bacterial Protein LAG-HRP Conjugate
}

\author{
Angel Justiz-Vaillant ${ }^{1 *}$, Wayne Mohammed ${ }^{1}$, Sehlule Vuma ${ }^{1}$, Arvind Kurhade ${ }^{1}$ and Geeta Kurhade ${ }^{2}$ \\ ${ }^{1}$ Department of Para-Clinical Sciences, Faculty of Medical Sciences, The University of the West Indies, St Augustine Campus, Trinidad and Tobago, West Indies \\ ${ }^{2}$ Department of Pre-clinical Sciences, Faculty of Medical Sciences, The University of the West Indies, St Augustine Campus, Trinidad and Tobago, West Indies
}

"Corresponding author: Angel Justiz-Vaillant, Department of Para-Clinical Sciences, Faculty of Medical Sciences, The University of the West Indies, St Augustine Campus, Trinidad and Tobago, West Indies, Tel: +8687735914; E-mail: angel.vaillant@sta.uwi.edu

Rec date: Dec 14, 2015; Acc date: Jan 18, 2016; Pub date: Jan 20, 2016

Copyright: (c) 2016 Justiz-Vaillant A, et al. This is an open-access article distributed under the terms of the Creative Commons Attribution License, which permits unrestricted use, distribution, and reproduction in any medium, provided the original author and source are credited.

\begin{abstract}
Objective: To purify IgG molecules from several species by SpA-affinity chromatography and to study the interactions of mammalian IgGs with a peroxidase-labelled SpL, SpA and SpG conjugate (SPLAG-HRP) in an enzyme-linked immunosorbent assay (ELISA).

Materials and methods: The periodate method described by Nakane and Kawoi was used to prepare the SPLAG-HRP conjugate. The $10 \%$ non-denaturing sodium dodecyl sulphate polyacrylamide gel electrophoresis (SDS-PAGE) of sera and purified immunoglobulins was carried out to characterize molecularly the purified lgGs. The chicken IgY fraction was isolated by the chloroform-polyethylene glycol (PEG) method for its use as a negative control in the ELISA that was used to determine the affinity of different immunoglobulins to a SPLAG-HRP conjugate.
\end{abstract}

Results: The SpA-affinity chromatography and the 10\% non-denaturing SDS-PAGE of sera and purified immunoglobulins (IgGs) were useful separation techniques. Most purified IgGs interacted moderately with the SPLAG-HRP including IgGs from horse, dog, skunk, coyote and raccoon. The purified mammalian IgG had a molecular weight (MW) of approximately $150 \mathrm{kDa}$.

Conclusion: The SPLAG-HRP was a versatile heterofunctional reagent useful for the detection of purified immunoglobulins from diverse mammalian species.

Keywords: Immunoglobulins; IgG molecules; Bacterial receptors; ELISA

\section{Introduction}

Immunoglobulin-binding bacterial proteins (IBBP) are bacterial receptors for immunoglobulins. They protect bacterial species from the immune system [1]. The most well-known IBBP are: Staphylococcal protein A (SpA) [2], Streptococcal protein G (SpG) [3] and Peptostreptococcal protein L (SpL) [4]. They have been used linked to enzymes in enzyme-linked immunosorbent assays (ELISAs) [5]. In this paper we described the purification of IgG molecules by SpA-affinity chromatography and the interactions of mammalian IgGs with a peroxidase-labelled SpL, SpA and SpG conjugate (SPLAG-HRP) in an enzyme-linked immunosorbent assay (ELISA).

\section{Materials and Methods}

Horseradish peroxidase (HRP) labelled SpA, SpG or SpL conjugates were prepared using the periodate method described by Nakane and Kawoi [6,7]. The SpLAG-HRP conjugate was prepared by mixing at room temperature $50 \mu \mathrm{l}$ of each SpL-HRP, SpA-HRP and SpG-HRP [5]. A commercially prepared protein-A antibody purification kit (Sigma-Aldrich Co, St. Louis Missouri) was used to purify IgG molecules from the serum of different mammalian species including horse, dog, coyote and others [8]. The 10\% non-denaturing sodium dodecyl sulphate polyacrylamide gel electrophoresis (SDS-PAGE) of sera and purified immunoglobulins was carried out [9].

The chicken IgY fraction was isolated by the chloroformpolyethylene glycol (PEG) method [10]. The eggs were washed with warm water and the egg yolk was separated from the egg white. The membrane was broken and the egg yolk collected and diluted 1:3 in phosphate buffered saline (PBS), $\mathrm{pH}$ 7.4. To $1 / 3$ of the egg yolk mixture an equal volume of chloroform was added, the mixture was then shaken and centrifuged for $30 \mathrm{~min}(1000 \times \mathrm{g}, \mathrm{RT})$. The supernatant was decanted and mixed with PEG $6000(12 \%, w / v)$, stirred and incubated for $30 \mathrm{~min}$ (RT). The mixture was then centrifuged as previously described. The precipitate containing IgY was dissolved in PBS $(\mathrm{pH}$ 7.4) at a volume equivalent to $1 / 6$ of the original volume of the egg yolk and dialyzed against $1 \mathrm{~L}$ of PBS (pH: 7.4 for $24 \mathrm{~h}$ at $4^{\circ} \mathrm{C}$ ). The chicken IgY was removed from the dialysis tubing. IgY concentration was determined by the Bradford method. IgY samples were stored at $20^{\circ} \mathrm{C}$.

The ELISA description is as follows and briefly, the microplates were coated with diverse purified IgG, $25 \mu \mathrm{l}(1 \mathrm{mg} / \mathrm{ml})$ per well in $50 \mu \mathrm{l}$ of carbonate bicarbonate buffer $\mathrm{pH} 9.6$ and reacted with the SPLAG-HRP. $50 \mu \mathrm{l} \mathrm{of} 3 \mathrm{mg} / \mathrm{ml} \mathrm{o}$-phenylenediamine solution (OPD) was added and the plates were incubated 15 minutes at RT. The reaction was stopped with $50 \mu \mathrm{l}$ of $3 \mathrm{M} \mathrm{H}_{2} \mathrm{SO}_{4}$ solution. The plates were read in a microplate reader at $492 \mathrm{~nm}$. Washing procedures were performed at every step. The protein binding was classified as negative: a mean of optical 
Page 2 of 2

absorbance (MOA) below 0.9 (-), low with a MOA between 0.91-0.20 $(+)$, moderate with a MOA between 0.21-0.40 (++) and high with a MOA of 0.41 or higher $(+++)$ [11].

\section{Results and Discussion}

Lane 1 molecular weight (MW) marker, lane 2 mule serum, lane 3 mule IgG, lane 4 donkey serum, lane 5 donkey IgG, lane 6 horse serum, lane 7 horse IgG, lane 8 dog serum, lane 9 dog IgG, lane 10 skunk serum, lane 11 skunk IgG, lane 12 coyote serum, lane 13 coyote IgG, lane 14 raccoon serum and lane 15 raccoon IgG (Figure 1).

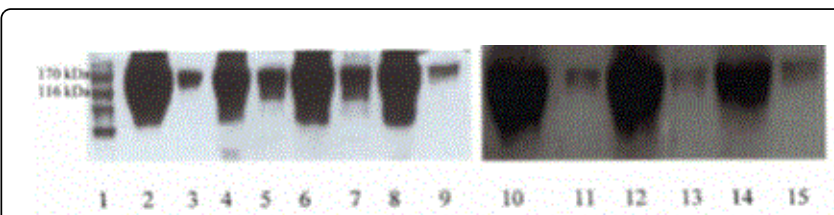

Figure 1: The $10 \%$ non-denaturing SDS-PAGE of sera and purified immunoglobulins (IgGs).

A commercially prepared protein-A antibody purification kit (Sigma-Aldrich Co, St. Louis Missouri) based on affinity chromatography was used to purified IgG molecules from the above different mammalian sera. The purified mammalian IgG had a MW of approximately $150 \mathrm{kDa}$ (Table 1 ).

\begin{tabular}{|l|l|}
\hline Mammalian Immunoglobulins & $\begin{array}{l}\text { Binding affinity to Protein } \\
\text { LAG-peroxidase (SPLAG-HRP) }\end{array}$ \\
\hline Horse IgG & ++ \\
\hline Donkey IgG & + \\
\hline Mule IgG & ++ \\
\hline Dog IgG & ++ \\
\hline Skunk IgG & ++ \\
\hline Raccoon IgG & ++ \\
\hline Coyote IgG & ++ \\
\hline Human IgG (+ control) & +++ \\
\hline Chicken IgY(- control) & - \\
\hline
\end{tabular}

Table 1: Reactivity of purified immunoglobulins with SPLAG-HRP.

Most immunoglobulins have a moderate binding capacity except that of the human IgG that was used as a positive control in the ELISA. Chicken IgY shows no binding affinity to SPLAG-HRP and was used as a negative control. The new contributions of this paper include the identification of IBBP as valuable reagents for the detection of IgG molecules in species of domestic and wild animals. It is important to detect antibodies as a marker of infection in coyotes, raccoon and skunks as they may be reservoir of rabies, an important zoonotic disease.

The affinity chromatography allows for the purification of immunoglobulins from diverse mammalian species. It also confirmed the results of the SpA reactivity with several mammalian IgG [1]. The affinity chromatography could be an important technology for the production of purified immunoglobulins, which could be used in the treatment of several animal and human diseases [12] or used as reagents in immunochemistry and molecular biology [13]. An important result of this study was the efficacious application of the periodate method in the preparation of conjugates that proved to be effective in the ELISA.

\section{Conclusion}

The purification of IgG molecules by SpA-affinity chromatography was successful. The SPLAG-HRP was a versatile heterofunctional reagent useful for the detection of purified immunoglobulins from diverse mammalian species.

\section{References}

1. Justiz-Vaillant A, Akpaka PE, McFarlane-Anderson N, Smikle MF (2013) Comparison of Techniques of Detecting Immunoglobulin-binding Protein Reactivity to Immunoglobulin Produced by Different Avian and Mammalian Species. West Indian Medical Journal 62: 12-20.

2. Richman DD, Cleveland PH, Oxman MN, Johnson KM (1982) The binding of staphylococcal protein A by the sera of different animal species. J Immunol 128: 2300-2305.

3. Higgins DA, Cromie RL, Liu SS, Magor KE, Warr GW (1995) Purification of duck immunoglobulins: an evaluation of protein $A$ and protein $G$ affinity chromatography. Vet Immunol Immunopathol 44: 169-180.

4. Björck L (1988) Protein L. A novel bacterial cell wall protein with affinity for Ig L chains. J Immunol 140: 1194-1197.

5. Justiz-Vaillant A, McFarlane-Anderson N, Wisdom B, Mohammed W, Vuma S, et al. (2013) Immunoglobulin-binding Bacterial Proteins (IBP) Conjugates and their Reactivity with Immunoglobulin in Enzyme-Linked Immunosorbent Assays (ELISA). Journal of Analytical \& Bioanalytical Tech 4: 175.

6. Nakane PK, Kawaoi A (1974) Peroxidase-labeled antibody. A new method of conjugation. J Histochem Cytochem 22: 1084-1091.

7. Nygren H, Hansson HA (1981) Conjugation of horseradish peroxidase to staphylococcal protein A with benzoquinone, glutaraldehyde, or periodate as cross-linking reagents. J Histochem Cytochem 29: 266-270.

8. Justiz-Vaillant A, Akpaka PE, McFarlane-Anderson N, Smikle MF, Wisdom B (2012) Purification of Immunoglobulin Y (IgY) from the Ostrich (Struthio camelus) by Staphylococcal Protein a (Spa) Affinity Chromatography. Journal of Chromatography \& Separation Techniques 3: 127.

9. Neville DM Jr (1971) Molecular weight determination of protein-dodecyl sulfate complexes by gel electrophoresis in a discontinuous buffer system. J Biol Chem 246: 6328-6334.

10. Polson A (1990) Isolation of IgY from the yolks of eggs by a chloroform polyethylene glycol procedure. Immunol Invest 19:253-258.

11. Stöbel K, Schönberg A, Staak C (2002) A new non-species dependent ELISA for detection of antibodies to Borrelia burgdorferi s. 1. in zoo animals. Int J Med Microbiol 291 Suppl 33: 88-99.

12. Justiz-Vaillant A, Vuma S, Mohammed W (2015) The use of intravenous immunoglobulins (IVIG) in immunological mediated diseases and possible mechanisms of actions. American Journal of Pharmacological Sciences 3: 33-37.

13. Justiz-Vaillant A, McFarlane-Anderson N, Akpaka PE, Smikle MF, Ramirez N, et al. (2013) Use of Dot Blots Analysis in the Separation of Anti-HIV Antibodies in Animals. Journal of Chromatography \& Separation Techniques 4: 181. 